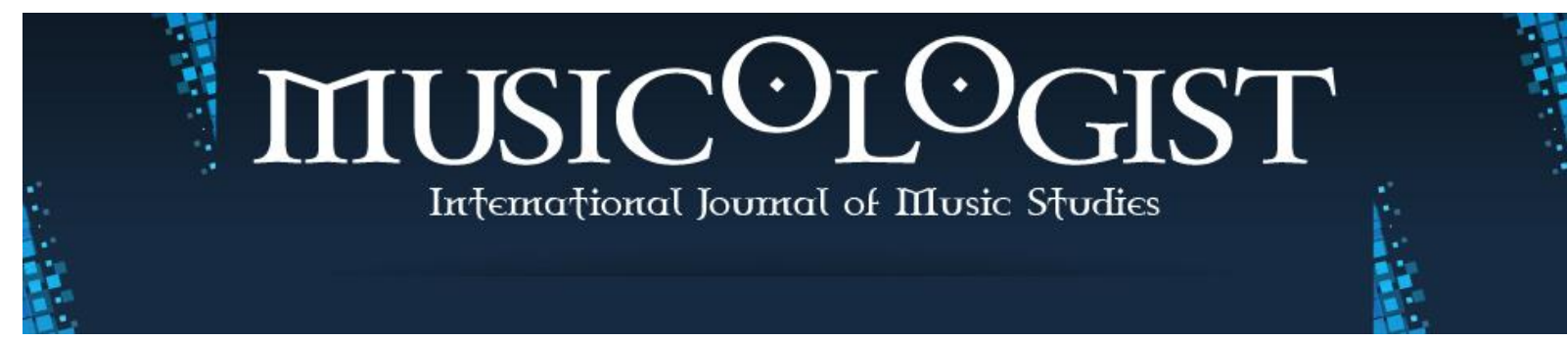

Trabzon University State Conservatory @ $2017-2021$

Volume 5 Issue 1 June 2021

Research Article

Musicologist 2021. 5 (1): 31-46

DOI: $10.33906 /$ musicologist.885272

FULYA UÇANOK ${ }^{1}$

Istanbul Technical University, Turkey

fulyaucanok@gmail.com

orcid.org/0000-0002-3260-7013

\title{
Towards a Response-able Electroacoustic Composition Practice: In Search of Sympoietic Multivalence
}

\begin{abstract}
This paper proposes a relational model for electroacoustic composition practice. In the model, relationality focuses on perspectives of responseability of the composer with more-than-human agents, within an entangled sympoietic musical space. Here, the response-practices are built on acts of listening that entail, aural analysis and embodied practice with material objects. Within the scope of this paper, morethan-human agents are narrowed down to only recorded sounds (fixed media sound files) and physical material objects.

In investigating such response-able compositional practices, the model follows Post-humanist and New-materialist strands focusing on various concepts proposed by Karen Barad and Donna Haraway. And in doing so, it aims to re-figure some of the conventional discourses about the concepts of poietic agency, and of multivalence within the composition practice.
\end{abstract}

\author{
KEYWORDS \\ Electroacoustic \\ composition \\ Response-able \\ composition \\ Sympoiesis \\ Material agency \\ Intra-action \\ Sound-based \\ composition
}

\footnotetext{
${ }^{1}$ Istanbul Technical University-MIAM (Doctorate Candidate); Istanbul Bilgi University (Research Assistant)
} 
This paper proposes a relational model for electroacoustic composition practice. In the model, relationality focuses on practices of cultivating response-ability of the composer with other humans and more-than-human agents, within an entangled sympoietic musical space. ${ }^{2}$

Here, the response -practices are built on a statement of aurality i.e., sound-as-heard. By privileging this position, the whole proposal revolves around resonances and potentialities of acts of listening -within entangled relations. These acts entail aural analysis and embodied forms of listening through sounding-with material objects.

Today, 'more-than-human' points to a post-anthropocentric thinking. Within the scope of this paper, more-than-human agents include other living beings, environments, and nonliving things, like inanimate materials. This paper especially focuses on relations with physical material objects/instruments and agents within recorded sounds (fixed media sound files). ${ }^{3}$ The human agents are narrowed down to improvising musicians.

In this study, the term response-ability follows paths introduced by the theoretical physicist and feminist theorist Karen Barad (2007), and scientist, philosopher, and feminist scholar, Donna Haraway $(1992,2016)$. Put briefly, response-ability, is the ability and/or capacity of oneself to respond to others. Within this study, I begin by specifically asking how such practice brings about the producing and sharing of knowledge in the musical context. Both Barad and Haraway's understanding of the production of knowledge is connected to and entangled with the social and material practices of the world. According to both scholars, the production of knowledge is read under the relational and requires response-abilities. Such stance, first and foremost, starts by the act of attending, noticing, caring, and allowing oneself to be affected and touched by the resonances that emerge within the relation. Attention and intention to notice are key here, as they rely on the premise that one shall perceive enough to be able to care enough.

\footnotetext{
${ }^{2}$ Taking in hand Donna Haraway's definition, sympoiesis is "a simple word; it means 'making-with'. Nothing makes itself; nothing is really autopoietic or self-organizing ... Sympoiesis is a word proper to complex, dynamic, responsive, situated, historical systems. It is a word for worlding-with, in company. Sympoiesis enfolds autopoiesis and generatively unfurls and extends it" (Haraway, 2016: 58).

${ }^{3}$ Here I take in hand a wide range of sound sources that could reside within a sound recording. These include living and non-living entities; which encompasses various musical contexts that either include or not, conventional approaches. The goal is to explore such experimental practice through various forms of relational agency with all sounds.
} 
In investigating such response-able compositional practice, the model follows poststructuralist, non-anthropocentric, feminist, and new-materialist strands, focusing on various concepts proposed by the theoretical physicist, and feminist theorist Karen Barad, and the scientist, philosopher, and feminist scholar Donna Haraway. And in doing so, it aims to re-figure some of the conventional ways to think about the concepts of poietic agency, and of multivalence within the electroacoustic composition practice.

\section{Basic Conceptual Framework}

Firstly, there is the need to establish a basic ground for what is meant by multivalence in this paper. Multivalence is a system that is capable of holding within it more than one value, application, interpretation, and/or meaning; therefore, the existence of dissimilar actors is a sine qua non. It is generally assumed that difference paves way for separatism and othering, suggesting power relations of I/other, insider/outsider that are based on binary categorizations. In order to setup a multivalent poietic space, there is the need to establish a logic of the 'and' rather than an 'either/or' one. This does not mean getting rid of the binary; it is about including it to form an expanded understanding of practicing the act of knowing through sound. Here, the logic of 'and' moves away from systems that have singular central figures of power and control.

Therefore, when practicing such multivalence in the musical domain, the model tends to move away from essentialist notion of the composer, which was painted as a power-and genius-oriented figure by the classic, early $19^{\text {th }}$ century paradigm.

The interest in practices of de-centering is not at all new to poeitic thinking in musical discourses: following a boom in the $20^{\text {th }}$ century, today we have many discourses that shake the conventional hierarchical top-down music making practices, scrambling the composer-audience-performer vector, and applying a sonic sensitivity to sounds and their sources. The practice proposed in this model partly presents a novel and experimental approach through introducing response-able, new-materialist perspectives.

It is important to note that the conventional, singular-power-oriented poietic figures and acts are not ostracized within this model. This position truly cannot be rejected all together, as it is inevitable that the poietic agent creates forms of hierarchies and control 
on various levels within the composition process. Some very obvious ones are: assumptions, capacities, motivations, and taste in the creative process during the compositional act. The goal of this research is not to address an ideal - ethical or moral - compositional strategy. The idea of rejecting and somewhat blacklisting an approach towards relations with sound and forms of musicking falls contrary to the main philosophy of multivalence. Even though not explicitly defined as an 'ethical model', it is inevitably interwoven, as the whole of the practice could be read under what Barad calls "ethico-onto-epistemological" approach, which is an enmeshed understanding of being, knowing, and valuing, wherein this practice directs exercise through its acts of caring, daring, and sharing. ${ }^{4}$ It is interested in thinking-by-sounding-with, exploring what a response-able composition practice might be like.

In opening up possibilities for such response-able practice, the model points out a spectrum of agentic capacities that are mostly overlooked in most of our electroacoustic discourses in composing-with recorded sounds and physical material objects.

The practice focuses on two main strands of actions that move simultaneously through the course of the composition process. The first is a perpetual inviting, joining-in, stayingwith and becoming-with agents, ranging from living to non-living entities. ${ }^{5}$ Such beingwith positions the composition process within an entangled multivalent space that opens up socio-musical imaginaries for response-able practices. ${ }^{6}$ And second strand consists of 'the I' generating and evaluating multiple instances of one's own responses to/with others through response-able acts. ${ }^{7}$ Both of these perspectives open up a space, in which the agents other than 'the I' are no longer the object of studies, but the generators of

\footnotetext{
${ }^{4}$ Barad states that she uses ethico-onto-epistemology to "foreground the entangled nature of ontology, epistemology, and ethics. The analytic philosophical tradition takes these fields to be entirely separate, but this presupposition depends on specific ways of figuring the nature of being, knowing, and valuing" (Barad, 2007: 409).

${ }^{5}$ Here I refer to Haraway's "Staying with the Trouble". She describes: "Staying with the trouble requires making oddkin; that is, we require each other in unexpected collaborations and combinations, in hot compost piles. We become-with each other or not at all. That kind of material semiotics is always situated, someplace and not no place, entangled and worldly" (Haraway, 2016: 4).

${ }^{6}$ In this paper, socio-musical imagination springs from the term "sociological imagination", which means to read things through a web and network of social connections, highlighting relational ontological positions.

${ }^{7}$ In this paper 'the I' is used as an umbrella term describing the first-person poietic agent (composer); an agent with an intentional desire to compose through a response-able practice. I avoid using the term composer because of its conventional centralized stance. In this paper 'the I' is understood as a multivalent entity of constant becoming, it repositions itself within the network of agents distributing centralized power relations through acts of listening, performing, composing.
} 
knowledge itself, opening up sympoietic potentiality. Therefore, the model does not propose a practice to study, 'musical objects' that are contained in and of themselves, but rather, a practice built on a continual relational network with other agents.

In unpacking such relationality, let's begin with Barad's concept of Intra-action (2007). Intra-action is unlike interaction, wherein entities already exist before they encounter one another, maintaining a level of independence. Intra-action proposes that entities emerge within their relationship, not outside of it. This goes hand in hand with Haraways's concept of the generative "becoming-with".

Haraway explains: "[i]f we appreciate the foolishness of human exceptionalism then we know that becoming is always becoming with, in a contact zone where the outcome, where who is in the world, is at stake" (Haraway, 2007: 244).

Both intra-action and becoming-with move away from prescribing agency a static and passive meaning, like a thing someone or something has, as if it is an individual property. Presupposing that these entities have an ability to act magnifies their agential, performative, and relational stance.

Barad's notion of agency expands beyond humans and living beings to matter material and discourse. In what she calls "agential realism", matter, living beings and discourse are intra-active and therefore inseparable: reality comes into being through intra-active agentiality (Barad, 2007: 90). From such perspective, the notion of reality is not fixed and agency is not an ontological given; there is a generative act of agentic capacities and constant becoming-with. Haraway states:

\footnotetext{
"Lynn Margulis knew a great deal about "the intimacy of strangers," a phrase she proposed to describe the most fundamental practices of critters becoming-with each other at every node of intra-action in earth history... I propose holoents as a general term to replace "units" or "beings"... I use holobiont to mean symbiotic assemblages, at whatever scale of space or time, which are more like knots of diverse intra-active relatings in dynamic complex systems, than like the entities of a biology made up of preexisting bounded units..." (Haraway, 2016: 60; emphasis mine).
}

In foregrounding such relations of humans, animals, organisms, technologies, objects, and environments, Haraway is interested in considering and tracing the constant 
entanglement of humans and more-than-humans, looking at how others change us, as well as how we change them through our relations.

Therefore, through such intra-active entanglement, a field of non-predetermined, nonlinear and generative listening-thinking-doing-with opens up. In the domain of sound, this understanding first and foremost puts forth an agent that simultaneously performs acts of listening and responding. And, more importantly, rather than listening/responding-to, 'the I' is interested in listening/responding-with.

In joining-in with the other, interest and curiosity are key words. Haraway re-situates the definition of response-ability through Hannah Arendt's words "to go visiting"8 . Haraway states:

\begin{abstract}
"Visiting is not an easy practice; it demands the ability to find others actively interesting, even or especially others most people already claim to know all too completely, to ask questions that one's interlocutors truly find interesting, to cultivate the wild virtue of curiosity, to retune one's ability to sense and respond-and to do all this politely! (Haraway, 2016: 127).
\end{abstract}

Therefore, a response-ability that builds on such a position, is not only about acknowledging agentic capacities and entanglement of relations, but incorporating such awareness into curious, attentive, and responsive practice of sounding-with.

In taking up such perspective, let us begin by look at the act of composing with recorded sounds.

\title{
Response-ability-with Recorded Sounds
}

With the practice of working with recorded sounds, the act of making the recording itself is a form of composing. If the sound recording is done by 'the I' her/himself, then there is already an inherent intra-action between the trio of environment, the recording machine, and 'the I'. But once the act of making the recording is taken out, we are left with a question. How is 'the I' to intra-act with those agencies that reside within sound recordings once the recording is made?

\footnotetext{
8 "To think with an enlarged mentality means that one trains one's imagination to go visiting" (Hannah Arendt, from Lectures on Kant's Political Philosophy; as cited in Haraway, 2016: 126).
} 
Once the sounds are recorded, the agents become sonic agencies within a material-fixedsound file. The agencies within the fixed-media recording cannot give real-time-response or feedback. Therefore, the relational plane is limited within appearances of the other on 'the I'. Consequently, this practice of response-ability follows a phenomenological understanding. As Diana Coole states, "Phenomenology does not begin with an idealist model of agents then seek their facsimile in the real world; rather it reads ambiguous signs of agentic expression as they emerge within a shared lifeworld" (Coole, 2005: 125).

Intra-activity then, occurs between various agentic capacities of the response-abilities of 'the I'. These capacities are generated by listening-with, staying-with, and doing-with the agents within the recorded sound. Accordingly, intra-action also simultaneously occurs with 'the I' and the co-habituated multivalent musical spaces. Although the other may seem limited because it cannot respond back, the recording is kept as is, without any heavy electronic manipulations. It is important for the model that sounds are recognizable and have strong source-cause relations with their sources. As the model is interested in cultivating response-abilities of 'the I', keeping the recorded sounds intact opens up a process for the composition, wherein 'the I' becomes-with the others and by moving simultaneously in/around/over/under them, opens up a form of entangled encounter. Therefore, the aim of the model is to work literality-with, not just with the metaphors of the other.

This stance, is not at all foreign to electroacoustic practices. Various strands of soundscape studies exemplify a practice that has a heightened sensitivity to sound and its cause within recorded sound files. Rather than treating the recorded sound as a disembodied sound file, soundscape practice has interest and a desire to recognize and look for various types of agencies within the sound and its context. And, more importantly, it is interested in the relationships of various agents and environments.

To exemplify one among various approaches in soundscape composition, let's take a look at Hildegard Westerkamp's approach. Here she expresses her relationship to two different living beings (a cricket and a raven) in two of her compositions in the in the process of composing with the recorded sound:

"I do feel that sounds have their own integrity and feel that they need to be treated with a great deal of care... I could not just manipulate it [cricket 
sound]. It had to be a sonic discovery journey to retain the level of magic for me. And I remember a moment in which I said "Stop". The journey was beginning to turn into electronic experimentation and the cricket was being obliterated. Same experience with the Raven Beneath the Forest Floor. I tried to make it into a regularly beating drum... it simply wouldn't let me. So, I returned to the shape of the original full call, slowed that down and received from it a drum-like sound. It took a whole day to fly into electronic land and return to the raven call" (McCartney, 2006: 33).

This is quite different from the form of decentering practiced by John Cage through his chance operations, where he lets indeterminate agents shape and/or change music without having a relational process with them per-se, as he is not interested in that.

In Westerkamp's approach, there is a sensitivity to sound and its source; an interest in the other, a desire to be in a relational space and a heightened sensitivity to the entangled co-creative space.

It is important to note that within such a position, there is also the modest understanding that underlines an awareness of the fact that we never truly understand the other. All forms of relation include a form of erasure of the actual, as something gets lost and/or rewritten during the transmission/translation taking place in the relation.

When we take this perspective form soundscape studies and adopt/adapt the relational stance of 'the I' to all sounds, a new window of composing posture opens up. ${ }^{9}$ In acknowledging various agencies of sound, one can begin listening and sounding differently from the conditioned ways of responses that come from the bulk of our discourses. Here it would be useful to introduce Casey O'Callaghan's ontological definition of all sounds:

"Sounds themselves... are particular individuals that possess the audible qualities of pitch, timbre, and loudness... They enjoy lifetimes and bear similarity and difference relations to each other based on the complexes of audible qualities they instantiate" (O'Callaghan, 2007: 17).

This brings us to an important topic connected to our musical discourses: the issue of language. The topic is much larger than the scope of this particular paper, however, it is

\footnotetext{
${ }^{9}$ Broadening the circle to also include physical material objects and other musical practices (Ex: various categories of recordings incorporating conventional or non-conventional instruments and agents).
} 
also important to point out the effects language has on our discourses. We find that assertive expressions in prevail in the language of electroacoustics; it attributes passive and static notions to sounds, which are to be 'controlled' and 'manipulated'. These are usually expressed through the use of metaphors, images, and symbols in describing sounds, behaviors, functions, processes, hardware, software etc. Such language carries on the practices of the power-oriented, centered composer figure. From 1990's on, this issue has been subject to critique by many scholars (McClary, 1991; McCartney, 2006; Bosma, 2006; Rodgers, 2010; to name a few), and today, there is a growing sensitivity to the language in the discourses of electroacoustics.

Passing on information to one another in adding to the common knowledge, and the discourses we build upon, language sits at the heart of much of our music-making practices. Such a shift of language consequently affects our perspectives, behaviors, and engagement strategies; therefore, it establishes the basic feature, in which we could begin to be a part of the discourses of symbiosis, in search of multivalence.

This being said, let us move on to the apparatuses that are used within the model to realize the response-able music making practice that we've built on so far.

\section{Musical Apparatuses}

The model uses objective musical apparatuses in describing sounds and their behaviors, for guiding both the listening experience of aural analyses and response practices of 'the I'. The apparatuses function to open up multiple agentic capacities of both the other and 'the I'.

Firstly, the model takes up a sound-based approach and spectromorphological descriptions of sounds. And secondly, it incorporates kinetic, gesture-based models called Temporal Semiotic Units ${ }^{10}$ (TSU), helping to guide the relational experience of 'the I'.

The term sound-based is coined by Leigh Landy to describe music that is based on a wide range of sound types that fall outside the solely note-based organizations. This opens up a musical understanding that provides equal ground to various sound types that are

10 Les Unités Sémiotiques Temporelles (UST) 
more-than solely pitch-based structures. In the model, these sounds are described through spectromophological terminology.

Spectromorphology is s term coined by Denis Smalley for describing sound shapes, based on the interaction between the sound spectra (hence spectro-) and the way it changes (morphs) through time. It is a descriptive tool for aural perception. Any sound, one way or another, could be described through a spectromorpholocial description, ranging from traditional instruments to everyday objects, from soundscapes to many other electroacoustic practices.

Both the sound-based approach and spectromorphological terminology are used because they allow to connect a wide range of sound types and sources within an equal, common ground. It is of value to note here that seeking such equality doesn't mean seeking sameness. Equality in this case, is about gathering a variety of sounds (perception of these sounds) within a shared multivalent plane afforded by these apparatuses, in order to investigate differences and possible relationalities.

Secondly, the model is interested in a movement-based approach i.e. reading behaviors of sounds through various motion models. In doing so, the model uses Temporal Semiotic Units, which have been devised in 1992 at the Laboratoire Musique de Informatique de Marseille (MIM) by a group of composers and artists led by François Delalande. These gesture units are used to describe kinetic motions through both their morphological descriptions and semantic meanings. On top of this, the units are devised to function within the sound and visual domains, providing a container that affords holding both. Having such a system that is defined, yet able to be re-territorialized, is an apparatus that is capable of producing pluralities. The TSU's function to be companions for the listening experience, directing the intentionality of the listening through sets of morphologies and semantic meanings presented in these units.

From both the analysis and performance perspective, neither the sound, nor the movement apparatuses presented above function to pin down acoustic elements through scriptural reading, but rather act as companions in supporting consciousness of 'the I'. These tools afford relational acts, allowing multiplicities of readings, and are not set up to produce absolute, fixed-form results. This, as a result, affords diffusing monolithic ways of listening and acting. And so, through such aural analysis of describing sound 
types and motions, the aim is to generate various affective traces of the agents on 'the I'. Usually, one ends up with more than one interpretation of sounds and motions.

\section{Embodied Response-ability with Inanimate Physical Material}

After the aural traces have been generated, 'the I' moves into a tactile form of listening, i.e. listening through embodied-performative-responses. By switching apparatuses from aural to tactile, a series of leakages and ruptures are generated between perspectives. These are then used as tools to disorient and de-center a fixed, authoritarian poietic figure. In moving to the tactile performance phase, one more agent joins into the assemblage: the inanimate material object.

The 'material' in music-making practice can mean many things, from the physical electronic hardware to various acoustic objects that could be categorized under conventional and non-conventional musical instruments, form digital interfaces to the sound file itself - and the list can go on.

In this paper, the model looks at materials that are limited to only physical acoustic objects used as musical instruments. Such objects include non-conventional materials used in musical ways, and/or conventional instruments used in either traditional or nontraditional ways. What is common to all, is that 'the I' interacts with all materials through a sound-based and gesture-based approach.

Here, the model takes up a rather unconventional view of adopting new materialist thought, into intra-action of human 'I' with materials. Instead of assigning static and passive stance to the materials, the poietic agent pays attention to possible agentic affects the material has on oneself.

A useful ground to building a new-materialist perspective is through Guy Reibel's practice of play-sequence. Reibel devised and taught play-sequence (Séquence-jeu) first at Paris Conservatoire national Supérieur de Musique et de Danse de Paris (CNSMD) in 1975 for teaching electroacoustics. Play-sequence is practiced by means of a performer, a sounding object-body, and a microphone, where the composer explores various gestures of sounding capabilities of the object (and of course, one's own capabilities). The reason 
Reibel devised such practice was to introduce intentionality that links gestural and bodily listening and composing 11 into the musicking ${ }^{12}$ practice.

If we carry play-sequence into new-materialist thought, we end up opening agential capacities of material, and 'the I'; consequently, possibilities of intra-action. In the proposed model, the practice of intra-active relationality with material agency is realized through two concentrations. They relate to the affordances and indeterminate qualities of the materials in contact with 'the I'.

The first practice is through affordances and expressive capabilities of material bodies, including bodies of both the inanimate object and 'the I'. Every physical material has a body, and a way that their body can physically interact and move with a human body. So, this perspective is highly embodied, opening the practice up to a form of carnal composition. It entails paying attention to and observing how one's own body moves, the possible gestures, in which interaction is possible, and is realized through a constant series of embodied feedback loops.

The second practice is based on intra-action with material that have indeterminate qualities of sound production. In other words, engaging with materials that have unstable and unforeseeable sound qualities and behaviors wherein sounds are not fully controllable to every extent by 'the I'. For example, 'the I' might expect a particular sound to occur with its interaction with the object, but the sounding result might be different, which, in return, changes the following response of 'the I', creating a dialogic relation, yet again pursuing the practice of de-centering.

\footnotetext{
${ }^{11}$ Annette Vande Gorne in her book Treatise on Writing Acousmatic Music on Fixed Media introduces a series of gesture archetypes to serve as tools in practicing the play-sequence. She explains play-sequence as: "In summary, play-sequence is a recorded musical phrase, two or three minutes long, obtained in a single continuous performance based on a single method of playing a single sound body" (Vande Gorne, 2018: $10)$.

12 "Musicking" is a term coined by Christopher Small to include all acts related to a wide definition of 'performing' music. He explains: "The essence of music lies not in musical works but in taking part in performance, in social action. Music is thus not so much a noun as a verb, 'to music'. To music is to take part in any capacity in a musical performance, and the meaning of musicking lies in the relationships that are established between the participants by the performance. Musicking is part of that iconic, gestural process of giving and receiving information about relationships which unites the living world, and it is in fact a ritual by means of which the participants not only learn about, but directly experience, their concepts of how they relate, and how they ought to relate, to other human beings and to the rest of the world" (Small, 1999: 9).
} 


\section{Multiple Outputs: Outputs of Multiplicities}

In expressing these affective traces and becomings, generated-with both agents within sound recordings an and physical material bodies, the goal is to explore multiple possible responses, created through response-able acts. Consequently, the musical work ends up having multiple manifestations through various relational configurations. By producing pluralities, 'the I' opens up multiple narratives where each such response has a particular kind of symbiosis, a particular self, and a particular kind of narrative. These spaces, selves, and narratives constantly let go of the previous versions. Through a constant repositioning, 'the I' practices performing re-distribution of one's own agential center, continually considering issues of power, desire, empathy, resistance, and affirming both acts of similarities and differences.

Not deciding in advance what is to become of the final work and generating multiplicities creates paradoxical situations, which are processes of constant composition and decomposition. The final question is, then, what is to be done with these multiple responses?

The model proposes evaluation of multiple responses through what is called 'diffractive methodology'. Diffractive methodology was first introduced by Haraway in 1992 and later developed by Barad in 2007. Haraway, Barad, and many education scholars propose diffractive methodology as a way of troubling dualisms. The Baradian approach, which ties to an intra-active stance, suggests reading one text through the other to create new patterns of ideas as a result of these intra-actions.

In the proposed musical practice, this functions to break one's biases. Gathering both aural and tactile information and constantly feeding them into one another through source and cause relations, scrambles one-sided linearity.

The whole process of reading one's own responses-with-others then becomes a series of enacting, differentiating, and entangling: i.e., dealing with a paradox. By disrupting itself through a system and a process, it aims to disrupt the conventional, paving ways for processes that lead into new ways of thinking, listening, acting, and relating.

As Walt Whitman said: "Do I contradict myself? Very well, then I contradict myself, I am large, I contain multitudes" (Whitman, 2005[1855]: 55). 
Having a large enough inner world to be able to hold together multitudes, and not being torn by paradoxes that come with spaces of pluralities, we can begin acting within multiplicities of oneself. Embracing such positionality, the model produces what the contemporary visual artist, psychoanalyst, and feminist theorist Bracha Ettinger would call metramorphose (1992). Metamorphose in biology is characterized by a change, wherein the changed version gets rid of its previous self. However, in Ettinger's neologism metramorphosis, by an additional ' $r$ ', the meaning changes to include both the changed self, as well as the self before the change has happened. Such a space then, paradoxically, can hold together both the singular and the multiple, the binary and the entangled, affording both and interactive, as well as an intra-active co-creation - i.e., multivalence.

Although presenting a final version of the musical work is possible, there is also the possibility of an explicit presentation: presenting the process of the work as the work itself. Such openness allows the work not to be reduced to one function. The process does not aim to produce accuracy of immediate experience nor an ultimate end-product, but a particular example of the process, a tracing of the experience and being explicit about it.

\section{Conclusion}

As Jacques Attali stated, "Music is more than an object of study: it is a way of perceiving the world. A tool for understanding" (Attali, 1985: 4).

Through a reworking of such poietic process through this particular model, informed by concepts and theories introduced above, we end up with an experimental practice of musical thinking and making. Such practice carries the potentiality to pave way for new ways of thinking-with and acting-with various agencies in the composition process, exploring forms of response-able symbiosis.

Through entangled response-able acts, agents co-exist and co-emerge over and over again within the experience of 'the I', generating multiple narratives. This may bring with itself narratives within narratives, multiplicity of spaces, and even, possibly, multiple belongings.

Informed by a socio-musical imagination, such poietic posture offers engaged insights to various forms of listening-with: a listening that neither rejects nor affirms another, but 
stays-with. I believe, that through such becoming-with-in, musical spaces of sympoiesis could have a potential to cultivate aware, caring, thoughtful outputs into the common record of our musicking practices.

\section{REFERENCES}

Attali, Jacques. (1985). Noise: The Political Economy of Music. Minneapolis: University of Minnesota Press.

Barad, Karen. (2007). Meeting the Universe Halfway: Quantum Physics and the Entanglement of Matter and Meaning. Durham and London: Duke University Press.

Bosma, Hannah. (2006). "Musical Washing Machines, Composer-Performers, and Other Blurring Boundaries: How Women Make a Difference in Electroacoustic Music" Intersections. 26(2): 97-117.

Coole, Diana. (2005). "Rethinking Agency: A Phenomenological Approach to Embodiment and Agentic Capacities" Political Studies. 53(1): 124-142.

Ettinger, Bracha, L. (1992). "Matrix and Metramorphosis" Differences: A Journal of Feminist Cultural Studies. 4(3): 176-208.

Haraway, Donna. (1992) "The Promises of Monsters: A Regenerative Politics for Inappropriate/d Others." The Monster Theory Reader, ed. Jeffrey Andrew Weinstock: pp. 459-521. Minneapolis: University of Minnesota Press.

Haraway, Donna. (2007) When Species Meet. Minneapolis: University of Minnesota Press.

Haraway, Donna. (2016). Staying with the Trouble: Making Kin in the Chthulucene. NC: Duke University Press.

McClary, Susan. (1991). Feminine endings: Music, gender, and sexuality. Minneapolis: University of Minnesota Press.

McCartney, Andra (2006). “Gender, Genre and Electroacoustic Soundmaking Practices”. Intersections: Canadian Journal of Music, 26(2): 20-48. 
O’Callaghan, Casey. (2007). Sounds: A Philosophical Theory. Oxford: Oxford University Press.

Small, Christopher. (1999). "Musicking-the meanings of performing and listening. A lecture" Music Education Research. 1(1): 9-13.

Rodgers, Tara. (2010). Pink Noises: Women on Electronic Music and Sound. Durham: Duke University Press.

Vande Gorne, Annette. (2018). Treatise on Writing Acousmatic Music on Fixed Media. Ohain: LIEN, Musiques \& Recherches.

Whitman, Walt. (2005). Walt Whitman's Leaves of Grass: the First (1855) Edition. ed. Harold Bloom, New York: Penguin Books. 